\title{
A $200 \mathrm{MHz} 35 \mathrm{MW}$ Multiple Beam Klystron for Accelerator Applications
}

\section{Final Report}

\author{
Grant Number DE-SC0000804 \\ Calabazas Creek Research, Inc. \\ 690 Port Drive \\ San Mateo, CA 94404 \\ (650) 312-9575, Fax: (650) 312-9536 \\ RLI@CalCreek.com \\ Principal Investigator: Dr. R. Lawrence Ives
}

Topic Number: 38

Subtopic Number: b 


\section{c. Introduction}

Calabazas Creek Research, Inc. (CCR) performed initial development of a compact and reliable $35 \mathrm{MW}$, multiple beam klystron (MBK) at $200 \mathrm{MHz}$ with a pulse length of $0.125 \mathrm{~ms}$ and a $30 \mathrm{~Hz}$ repetition rate. The device was targeted for acceleration and ionization cooling of a muon collider, but there are several other potential applications in this frequency range.

An MBK uses multiple beams propagating in individual beam tunnels to reduce space charge and allow reduction in the accelerating voltage. This allows a significant reduction in length over a single beam source. More importantly this allows more efficient and less expensive power supplies. At $200 \mathrm{MHz}$, the interaction circuit for a single beam klystron would be more than six meters long to obtain $50 \%$ efficiency and $50 \mathrm{~dB}$ gain. This would require a beam voltage of approximately $400 \mathrm{kV}$ and current of $251 \mathrm{~A}$ for a microperveance of 1.0. For an eight beam MBK with the same beam perveance, a three meter long interaction circuit would achieve the same power and gain. Each beam would operate at $142 \mathrm{kV}$ and 70A. Such parameters are achievable with solid state power supplies.

Communications \& Power Industries, Inc. (CPI) recently developed a $700 \mathrm{MHz}$ klystron for Los Alamos National Laboratory in support of the Accelerator Production of Tritium Project. This klystron, shown in Figure 1, is approximately the same size as the $200 \mathrm{MHz}$ klystron proposed here, even though it is more than three times the frequency. A single beam klystron at $200 \mathrm{MHz}$ would be more than twice the size of this klystron. This is a clear indication of the size reduction that can be achieved with multiple beams.

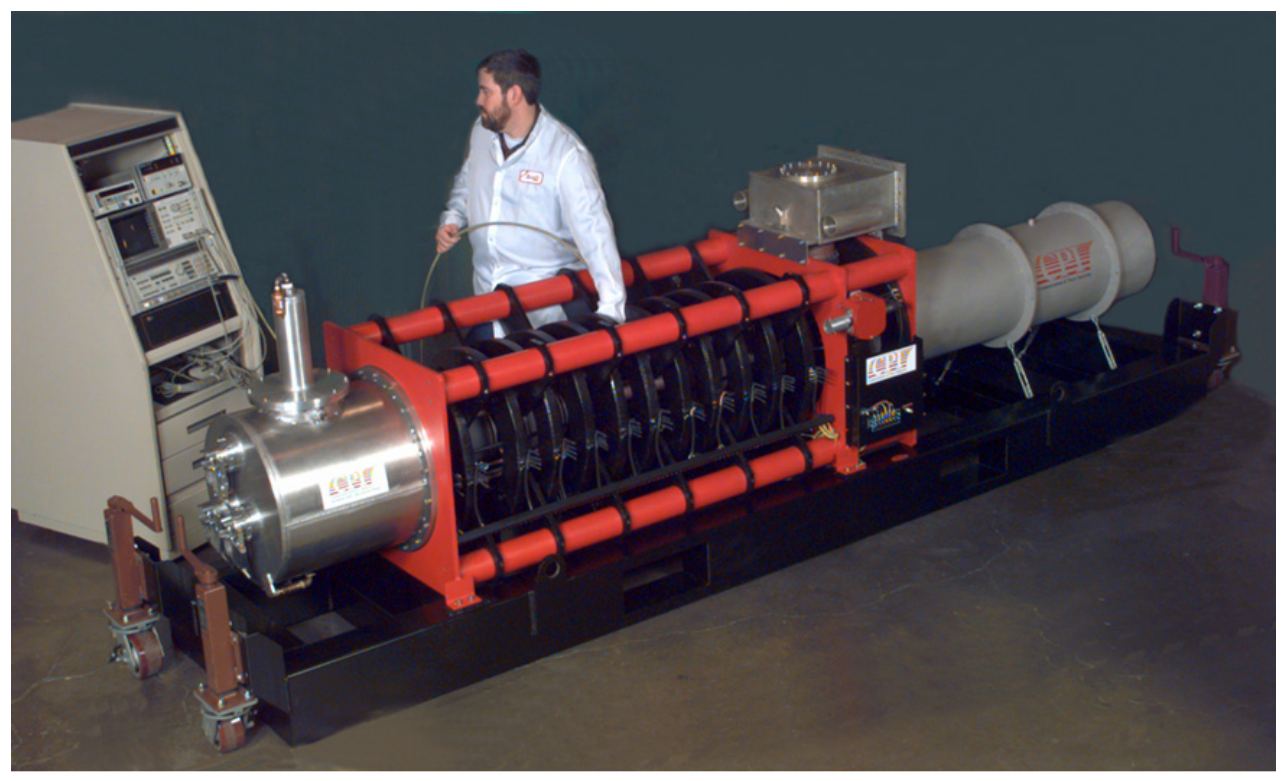

Figure 1. $700 \mathrm{MHz}$, single beam klystron developed by Communications and Power Industries

Figure 2 demonstrates scaling of beam voltage and current with the number of beams. CCR previously developed an eight beam, $100 \mathrm{MW}$, multiple beam gun $[1,2,3]$ and used it in a $50 \mathrm{MW}$ MBK at X-Band [4]. CCR also designed a $5 \mathrm{MW} \mathrm{MBK}$ at $200 \mathrm{MHz}$ [5] that incorporated eight beams. 
The MBK would incorporate long lifetime cathodes with little or no beam compression. The cathode and the interaction circuit would be completely immersed in a uniform magnetic field of approximately 300 Gauss. This makes the tube relatively simple to design and construct. This represents a new, innovative technique for designing high power RF sources in this frequency band.

The principal innovation, however, was dome cathodes

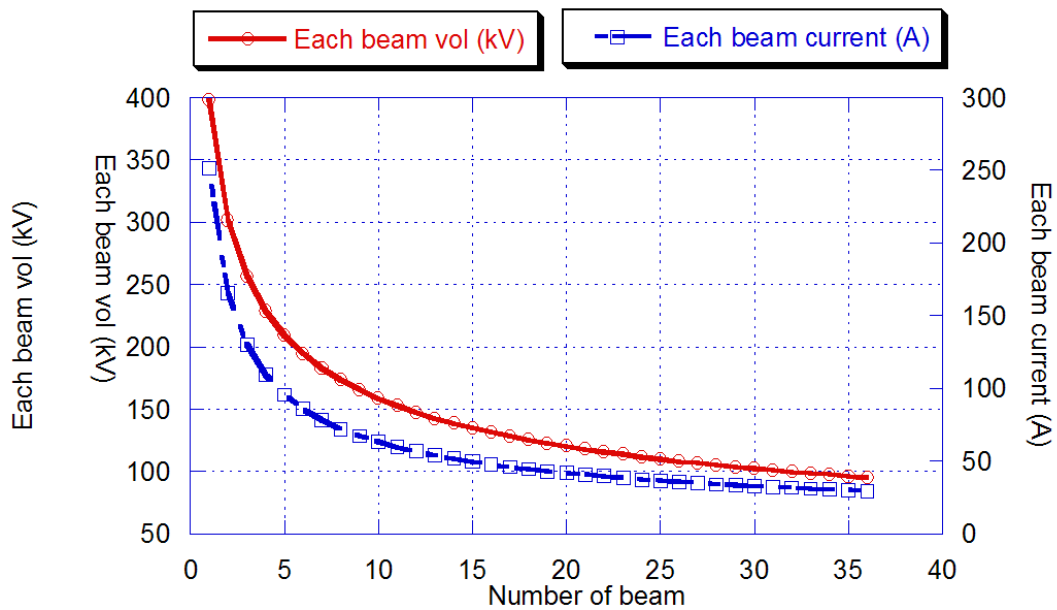

Figure 2. MBK beam current and voltage vs. number of beams to provide high beam quality in a simple, cost effective configuration. CCR developed the dome cathode gun in collaboration with North Carolina State University [6]. This unique design allows high beam quality for an electron gun immersed in a flat magnetic field. Flat magnetic field operation eliminates beam compression, increasing reliability while dramatically simplifying the beam optics design. For operation at this frequency, beam compression can be eliminated while still keeping the cathode current density sufficiently low for long lifetime operation.

The Phase I program developed a circuit using fundamental mode cavities that achieved the goals of the program. Fundamental mode cavities avoid potential competing modes. CCR utilized several RF circuit codes, including a klystron small signal code, the large signal codes KLSC, TESLA, and JPNDISK, and the RF field code High Frequency Structure Simulator (HFSS).

The Phase I design included:

- Eight electron beams

- Magnetic circuit, including one or more solenoids and field shaping iron

- Five cavity RF circuit with discrete, single gap cavities

- Coaxial input coupler

- Coaxial output with vacuum windows

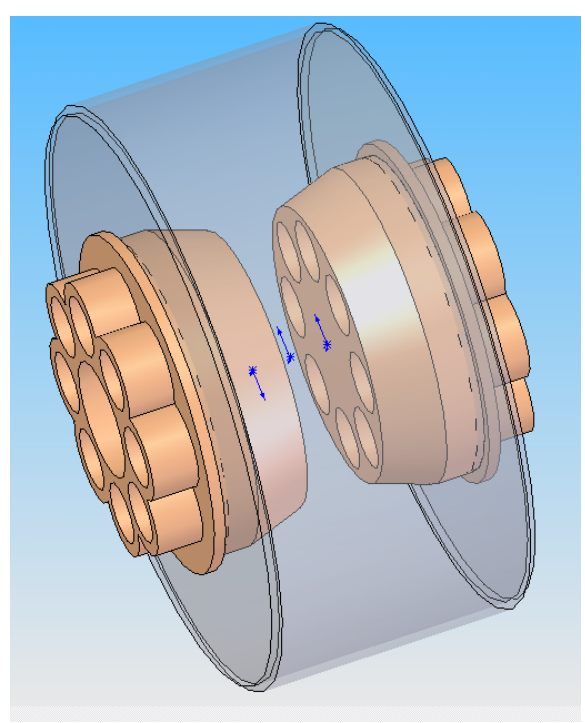

Figure 3. Circuit design for an eight beam MBK at $200 \mathrm{MHz}$

- Spent beam collector

The MBK design is predicted to generate $35 \mathrm{MW}$ at $200 \mathrm{MHz}$ with an efficiency of $48 \%$ and $51 \mathrm{~dB}$ gain. 
A multiple beam klystron would be ideal for a high power RF source at this frequency. Not only is the MBK significantly smaller than a single beam device, but the voltage reduction will dramatically reduce the cost of the power supplies and associated electronics. The multiple beam approach also provides a significant increase in total cathode area when compared with a single beam device. The anticipated cathode emission density would be approximately $3 \mathrm{~A} / \mathrm{cm}^{2}$, which should result in lifetimes exceeding 100,000 hours. Because the current emission density per beam is low, beam compression in the electron gun would not be necessary. This dramatically simplifies the beam optics design and allows for complete magnetic immersion of the gun and confinement of the electron beams in a magnetic field of approximately 300 Gauss.

During the Phase I program, CCR determined that the high voltage ceramic could be in air instead of oil. Communications \& Power Industries, Inc. developed this technique for horizontally installed klystrons. It considerably simplifies maintenance and reduces environmental and safety hazards.

The reduced voltage also results in improved performance, particularly in efficiency and bandwidth. This improved performance, coupled with the reduced size and cost of support equipment, makes a multiple beam klystron an ideal candidate for this application.

There is no other RF source available for producing this level of RF power in this frequency range. This new device would satisfy a requirement for high power RF sources for low frequency accelerators and colliders.

\section{d. Technical Objectives of Phase I Program}

The technical objective of the Phase I program was to design a $35 \mathrm{MW}, 200 \mathrm{MHz}$, multiple beam klystron consistent with muon collider applications. The target efficiency and gain were $50 \%$ and $45 \mathrm{~dB}$, respectively. The program included the following technical tasks:

- Task 1: Design a multiple beam electron gun with confined flow focusing

- Task 2: Experimentally verify operation of a dome cathode electron gun in a beam analyzer

- Task 3: Design a fundamental mode cavity without parasitic oscillations

- Task 4: Design an RF circuit meeting the performance specifications

- Task 5: Design additional components, including the magnet, input and output windows and couplers, and the spent beam collector

- Task 6: Develop a preliminary mechanical design for construction of the klystron

Results of these tasks is provided in the following section.

\section{e. Degree to which Phase I has Demonstrated Technical Feasibility}

The Phase I program was completely successful in demonstrating technical feasibility. All the technical performance specifications were achieved. The circuit efficiency demonstrated in the program, approximately $48 \%$, was slightly below the goal of $50 \%$. This seems to be a reasonable value for a pulsed tube, however, and is consistent with efficiency specifications provided during the program. 
The following section details the accomplishments for each task.

\section{Task 1. Design a multiple beam electron gun with confined flow focusing}

The Phase I program investigated several configurations for the electron gun in conjunction with the RF circuit design. As indicated in the Phase I proposal, this task investigated convergent, flat, and dome cathodes. Since convergent beams were not required, convergent cathodes were not considered, as the flat and dome cathodes offered significantly simpler designs. Simulations clearly indicated that higher beam quality was achieveable with the dome cathode. This configuration requires only a flat focus electrode for beam control in the cathode-anode region, providing an additional simplification in the design of the gun.

The design incorporates eight beams equally spaced on a ten inch radius circle. Each beam is $10.9 \mathrm{~cm}$ (4.3 inches) in diameter and conducts $70 \mathrm{~A}$ of current at $135 \mathrm{kV}$. The cathode current density is less than $1 \mathrm{~A} / \mathrm{cm}^{2}$, and the beam ripple is less than $2 \%$. A $200 \mathrm{G}$ magnetic field confines the beams. The magnetic field is constant through the gun and RF circuit, then decreases rapidly in the collector. Figure 4 shows simulation of one of the eight electron beams from the electron gun through a shortened circuit and into the collector. The shortened circuit reduces the simulation time.

Figure 5 shows a simulation of three of the beams. This simulation demonstrates that there is no interaction between the electron beams, either in the gun region or in free space regions of cavity gaps.

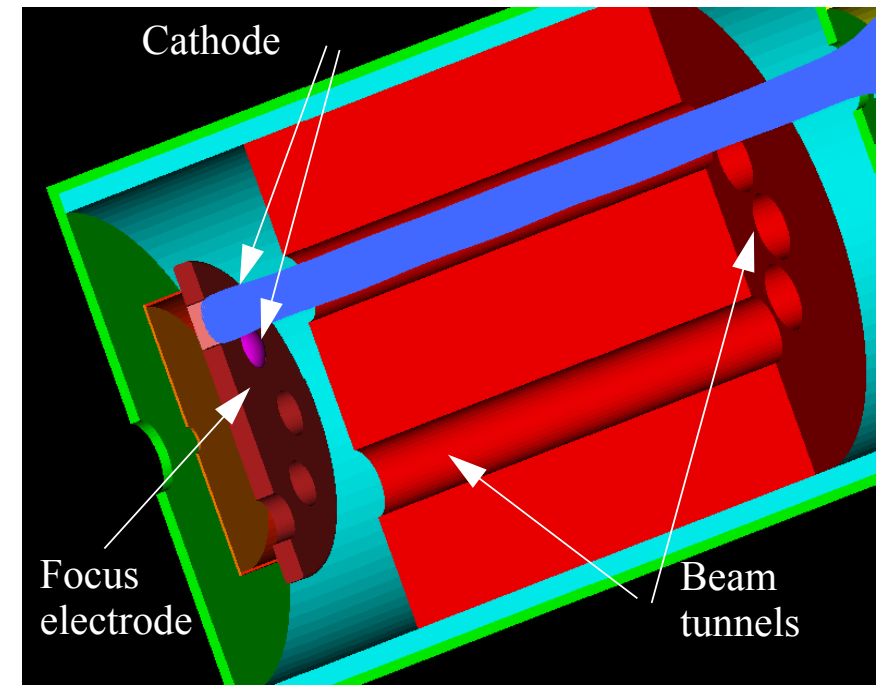

Figure 4. Eight beam electron gun geometry (sliced view)

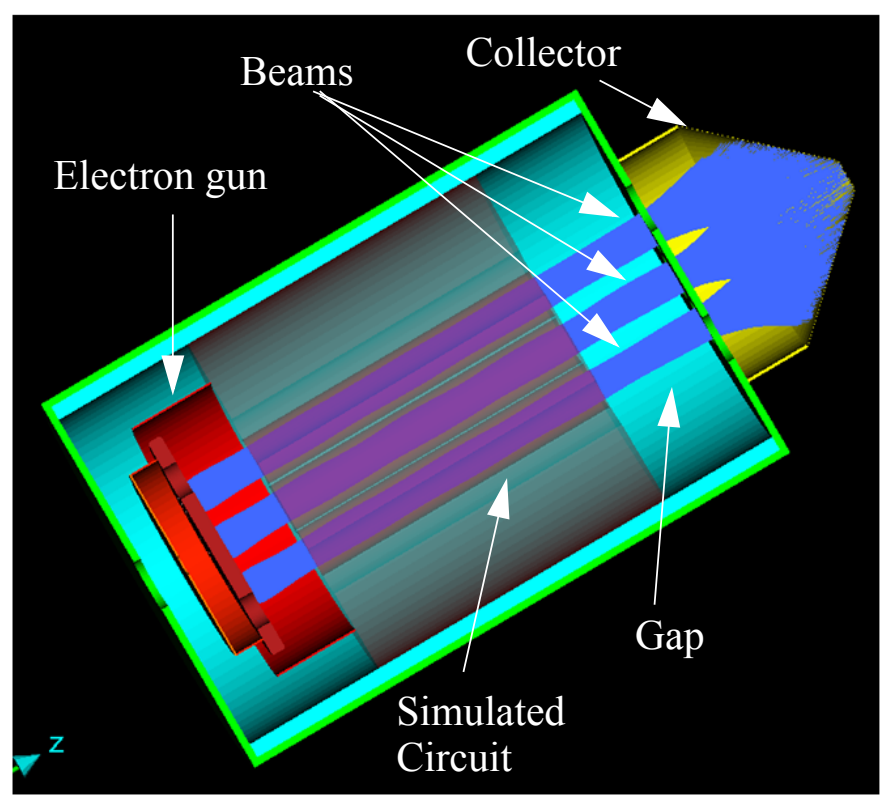

Figure 5. Simulation of three beams in a simulated RF circuit and collector 
The flat focus electrode eliminates field enhancement normally found on this electrode, minimizing the possibility of electrical arcing. Figure 6 shows a detailed view of the diode region showing three cathodes and the electric fields. The maximum field on the focus electrode is $9.95 \mathrm{kV} / \mathrm{cm}$, about an order of magnitude below typical values for $\mathrm{CW}$ operation. Consequently, electrical breakdown is essentially eliminated.

Simulations indicate that the design will produce very high quality electron beams with an extremely robust configuration. The simplicity and low electric field gradients provide a high confidence for success.

\section{Task 2. Experimentally verify operation of a dome cathode electron gun in a beam analyzer}

CCR attempted to experimentally verify operation of a dome cathode in its beam analyzer.

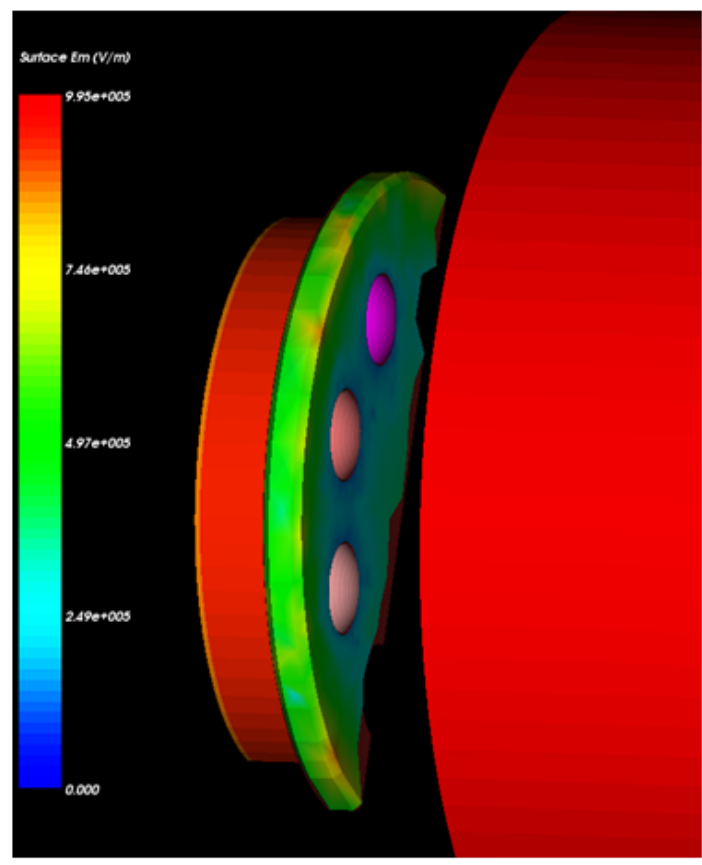

Figure 6. Close-up view of the electron gun showing three of the eight cathodes and the electric field on the focus electrode. Peak field is $9.95 \mathrm{kV} / \mathrm{cm}$. Unfortunately, delays by the vendor in fabricating the cathode prevented the test within the time frame of the Phase I program. The cathode was ordered in November 2009 and was delivered in May 2010, despite a quoted delivery of three months. Beam simulations indicated that a high quality electron beam would be produced using the beam analyzer geometry (Figure 7). Figure 8 shows a photograph of the dome cathode, receive in May 2010.

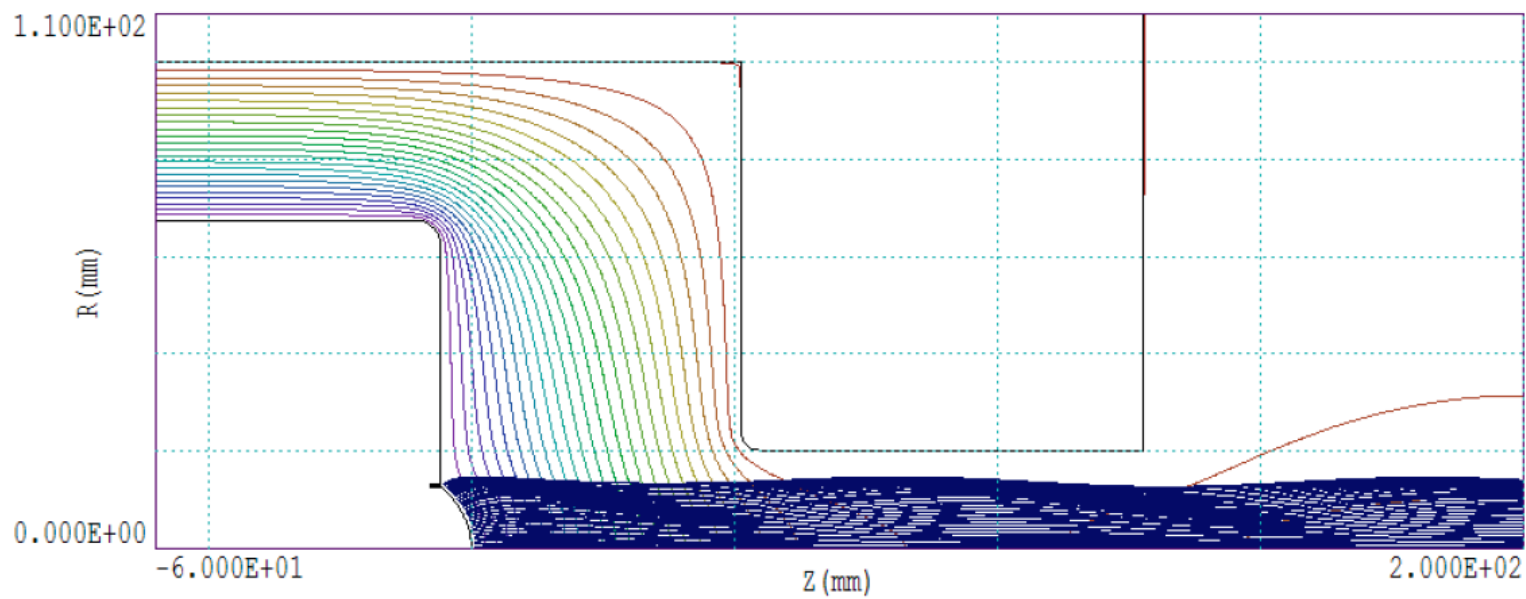

Figure 7. Simulation of test dome cathode

CCR initiated a detailed theoretical study of the dome cathode configuration to better understand the underlying physical principles. The initial configuration was empirically obtained by a computer optimization project that modified the cathode surface geometry and analyzed the resultant beam optics performance. It was this process that identified the dome cathode geometry as signif- 
icantly better than of convergent or flat cathodes in a constant magnetic field. Additional simulations indicated that the design was relatively immune to tolerance errors in concentricity and in relative position between the cathode and focus electrode.

The theoretical study confirmed the improved performance for beams subject to defocusing by anode lensing but was not completely successful in fully explaining the reasons. A report summarizing the results of the study is included with the proposal attachments. What was clear from the study was that dome cathodes can be modeled with existing codes just as accurately as conventional cathodes.

All parts are now available to perform the beam analyzer experiment, including the cathode and electromagnet.

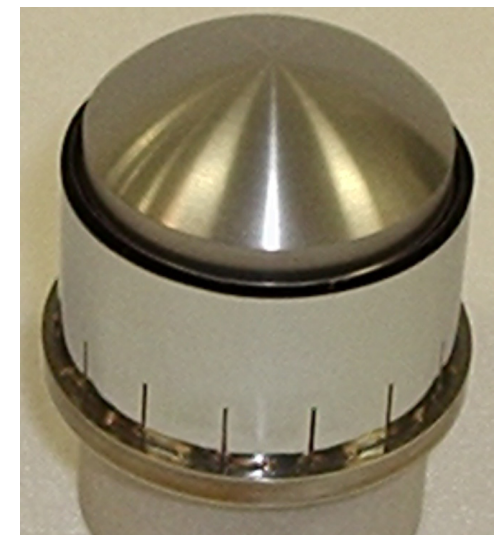

Figure 8. Dome cathode for beam analyzer experiment

A goal of the program was to implement fundamental mode cavities, thus avoiding problems with competing modes. Figure 9 shows a section of the five cavity circuit with transparent outer walls on two cavities. This shows that the cavities are reentrant around the ensemble of beam tunnels, but not around each individual tunnel.

The large signal performance was calculated using the codes KLSC [7] and TESLA [8,9]. KLSC simulates interaction of cavity fields with a single electron beam, while TESLA models both single and multiple beam interactions. Fields for KLSC are calculated using SUPERFISH, while TESLA

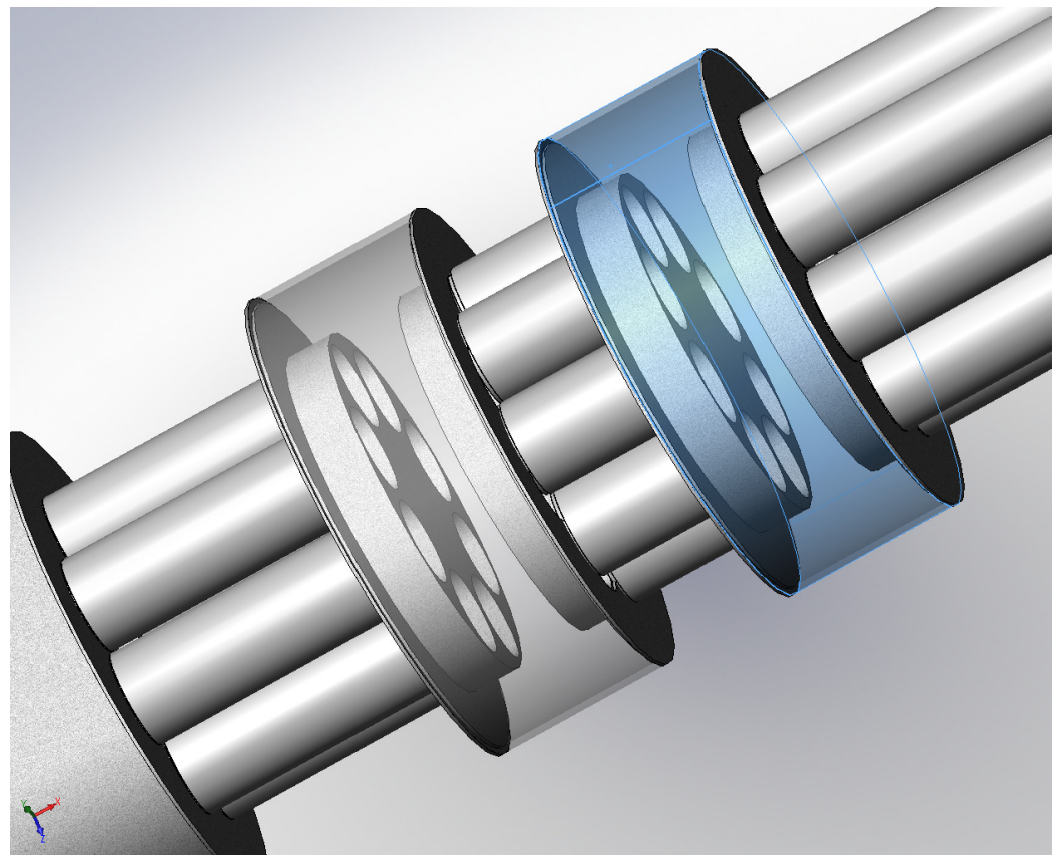

Figure 9. Section of five cavity circuit showing interior of two fundamental mode cavities uses the cavity gap fields at the drift tube wall radius as a basis, then self consistently calculates the fields at the beam using the telegrapher's equations. Consequently, these two codes calculate RF-beam interaction using entirely different approaches, so agreement in the results provides a high degree of confidence. In addition, two different CCR scientists executed the codes, which provides additional verification of the input.

For both KLSC and TESLA, the resonant frequency and R/Q were determined using Ansoft Corporation's High Frequency Structure Simulator (HFSS). The HFSS geometries for a buncher cav- 
ity and the output cavity are shown in Figure 10. Since the buncher cavities have eight-fold
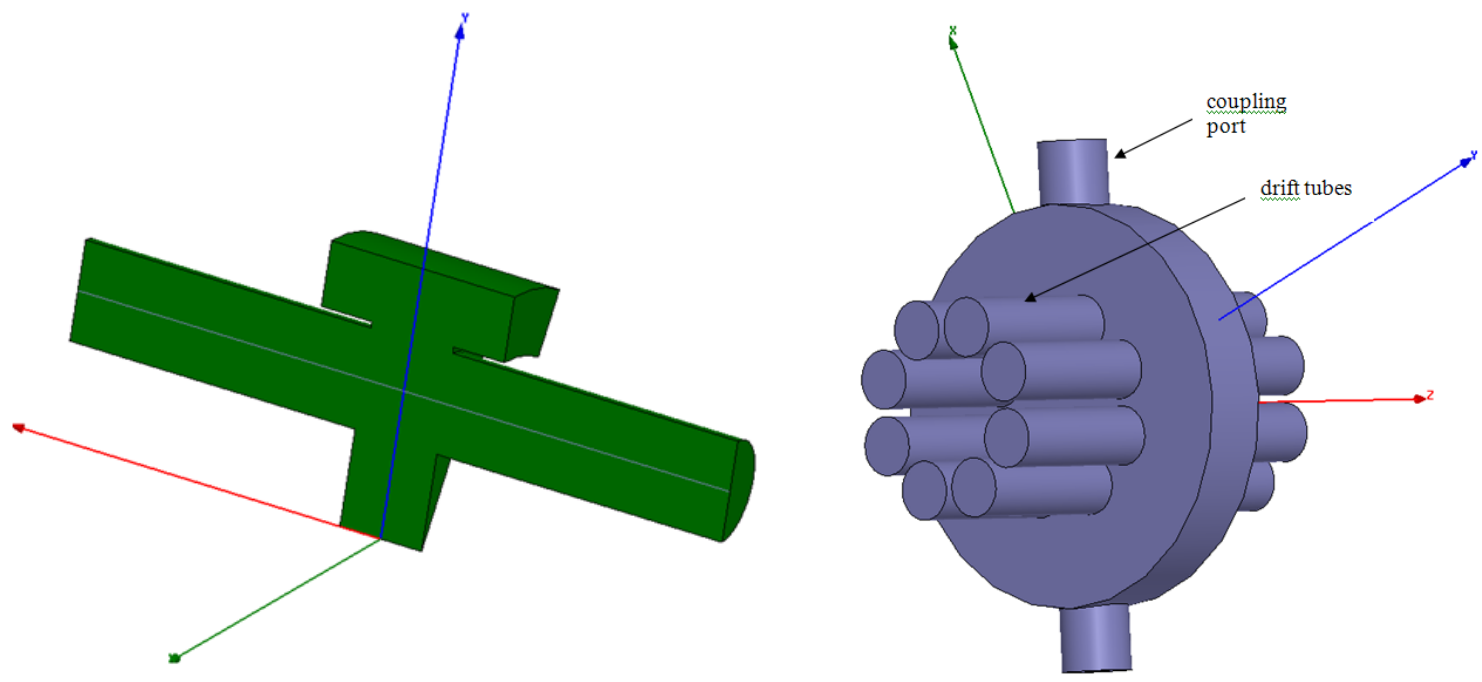

Figure 10. HFSS geometries for buncher cavity (left) and output cavity (right).

Symmetry can be used for buncher cavities to simplify the analysis.

symmetry, the model can be simplified to reduce the analysis time.

The cavities are $116 \mathrm{~cm}$ in diameter and $40 \mathrm{~cm}$ high. The diameter of the beam tunnels are $17 \mathrm{~cm}$, and they are equally spaced on a bolt circle diameter of $49.7 \mathrm{~cm}$.

Figure 11 shows the magnitude of the RF electric fields in the output cavity. As expected, the cavity gap fields are not azimuthally symmetric. There was concern about the accuracy of the TESLA and KLSC simulations, which assume symmetry. The field along the cavity radius and through the center of one of the waveguides is shown in Figure 12. To verify the method, R/Q was calculated by integrating Ez along eight lines parallel to the drift tube axis and regularly spaced around the beam envelope. The value obtained was essentially the same as that obtained by integrating along the center of the drift tube. This confirmed the accuracy of the simulations, assuming symmetry of the fields in the gaps.

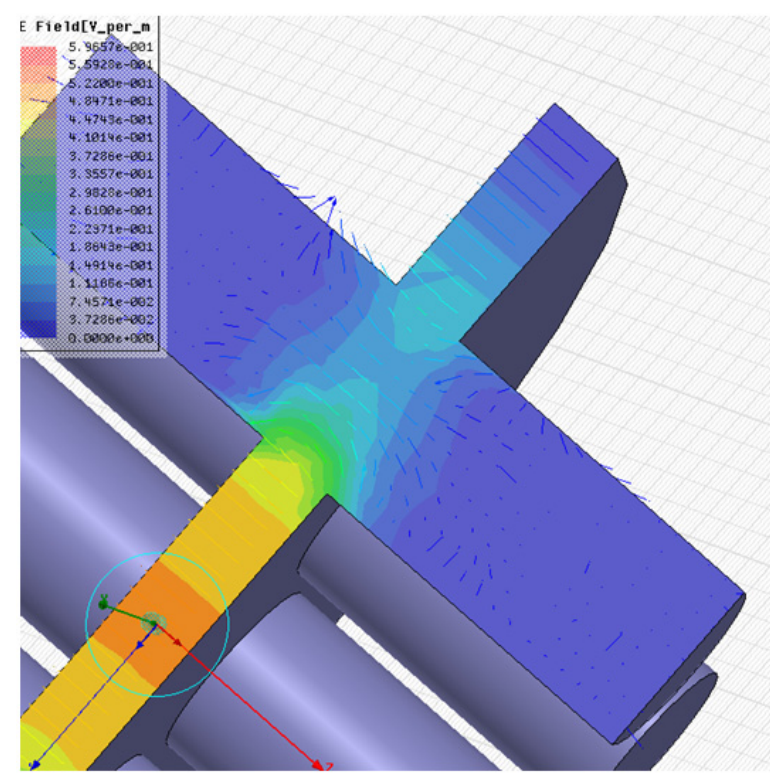

Figure 11. Electric field vectors and magnitudes in the output cavity 
This task successfully identified fundamental mode cavities that provide the required performance. These cavities will be relatively easy to fabricate, because of the simplicity of the design. The following section describes the performance of the cavities in the RF circuit.

Task 4. Design an RF circuit meeting the performance specifications

The initial modeling of the circuit used a standard small signal code and KLSC, with confirmation using TESLA. The modeling included a single beamlet with appropriately scaled values for R/Q. The results from the initial modeling are provided in Table 1.

Figure 12. Ez along a line from $\mathrm{x}=0, \mathrm{y}=0, \mathrm{z}=0$ to $\mathrm{x}=0, \mathrm{y}=1.15$ $\mathrm{cm}, \mathrm{z}=0$, showing the field distribution across the drift tube in the middle $(\mathrm{z}=0)$ of the cavity. The markers show the extent of the beam (with a fill factor of 0.7 ). Note that there is a significant variation in the field across the beam.

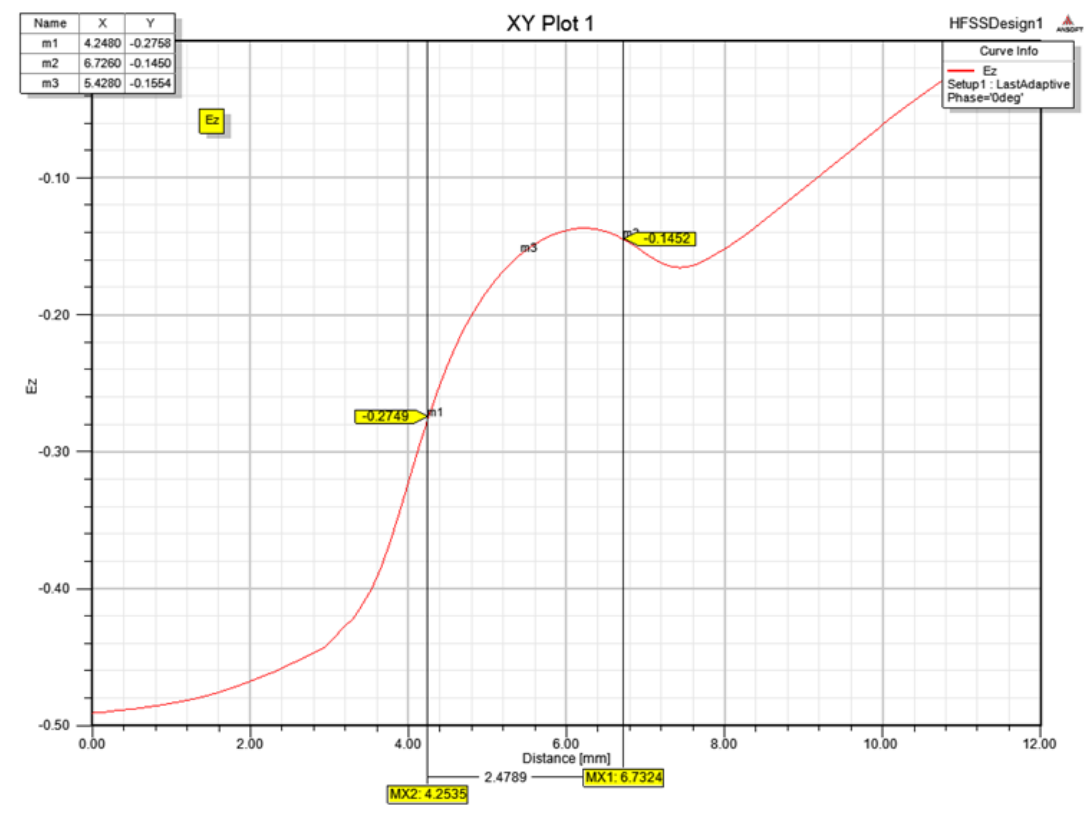

TABLE 1. Final Phase I Design Parameters

\begin{tabular}{|l|l|}
\hline Parameter & Value \\
\hline Beam Voltage & $142 \mathrm{kV}$ \\
\hline Beam current & $69.6 \mathrm{~A}$ \\
\hline Beam Perveance & 1.3 micropervs \\
\hline Center Frequency & 201.25 \\
\hline Output Power & $37.7 \mathrm{MW}(4.71 \mathrm{MW} / \mathrm{beam})$ \\
\hline Input RF Power & $36.7 \mathrm{~W}$ \\
\hline Efficiency & $47.7 \%$ \\
\hline Saturated Gain & $51.1 \mathrm{~dB}$ \\
\hline Drift Tube Radius & $8.5 \mathrm{~cm}$ \\
\hline Beam Filling Factor & 0.65 \\
\hline Magnetic Focusing Field & $278 \mathrm{G}$ \\
\hline
\end{tabular}


KLSC and TESLA predicted similar performance for the final circuit design. Table 2 compares the gap voltages in the cavities for the two codes.

TABLE 2. Cavity Gap Voltages in Final Phase I Circuit

\begin{tabular}{|c|cc|}
\hline Gap Number & KLSC (kV) & TESLA (kV) \\
\hline 1 & 1.1 & 0.825 \\
\hline 2 & 5.77 & 5.93 \\
\hline 3 & 26.4 & 28.1 \\
\hline 4 & 62.7 & 64.1 \\
\hline 5 & 170.9 & 170.5 \\
\hline
\end{tabular}

The RF output power predictions were also in agreement:

$\begin{array}{ll}\text { KLSC } & 37.68 \mathrm{MW} \\ \text { TESLA } & 39.68 \mathrm{MW}\end{array}$

The relative locations of the cavities are shown in Figure 13. Beginning at the input cavity, the axial positions of the cavity centers are at $0.3,0.9,1.5,3.0$, and 4.0 meters. These codes assume that the beam consists of concentric rings of electrons. Figure 14 compares the trajectories of these rings through the RF circuit. Note the relatively small level of radial modulation of the beam. The maximum radius on the vertical scale is the radius of the beam tunnel between cavities.

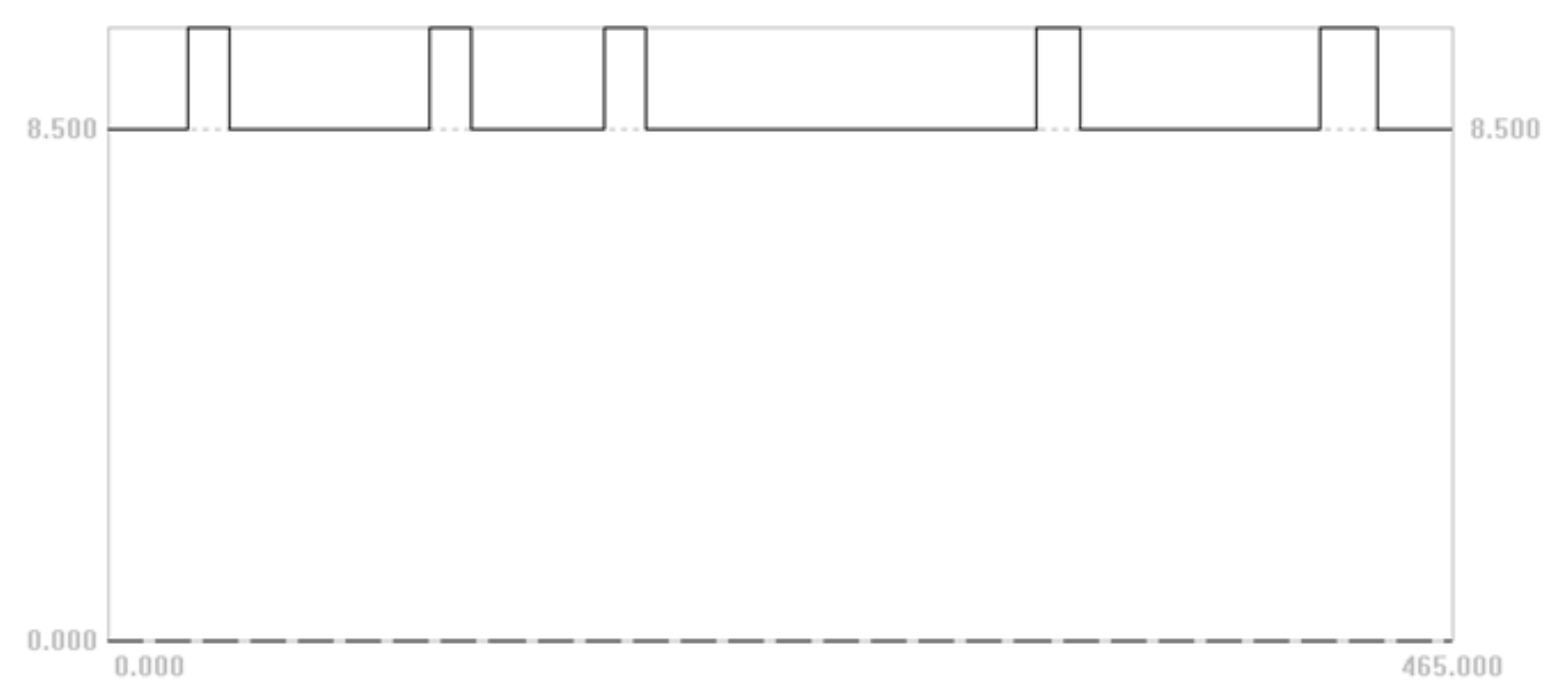

Figure 13. Relative axial location of the RF circuit cavities. Units are centimeters. 

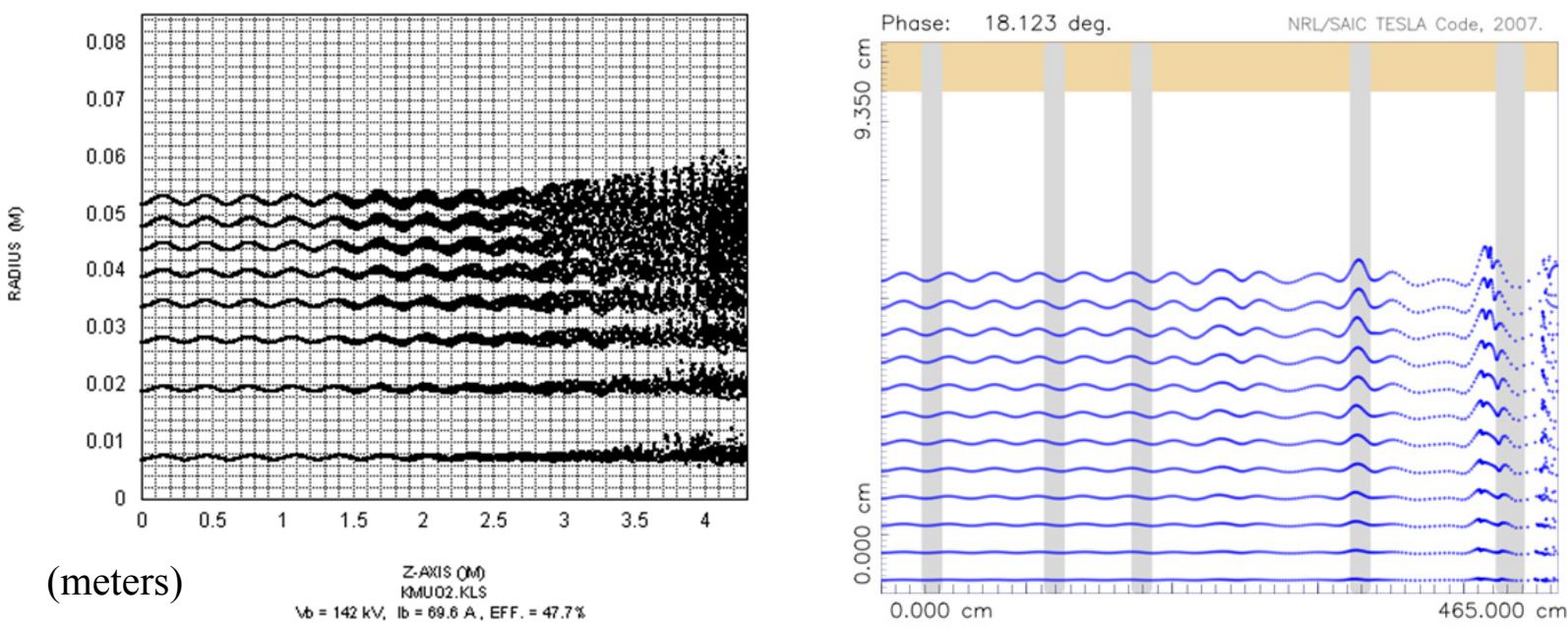

Figure 14. Ring trajectories predicted by KLSC (left) and TESLA (right)

Figure 15 compares the electric fields as calculated by KLSC and TESLA. KLSC, in conjunction with SUPERFISH, predicts a peak cavity gap electric field of $114 \mathrm{kV} / \mathrm{cm}$, well below the Kirkpatrick limit of $147 \mathrm{kV} / \mathrm{cm}$ at this frequency.

Figure 16 shows the predicted electron velocities as a function of axial position. KLSC predicts a positive velocity for all electrons, indicating that there are no reflected electrons. TESLA predicts negative energy electrons at a single phase of the RF cycle, but the duration is sufficiently short that no electrons are reflected out of the gap.
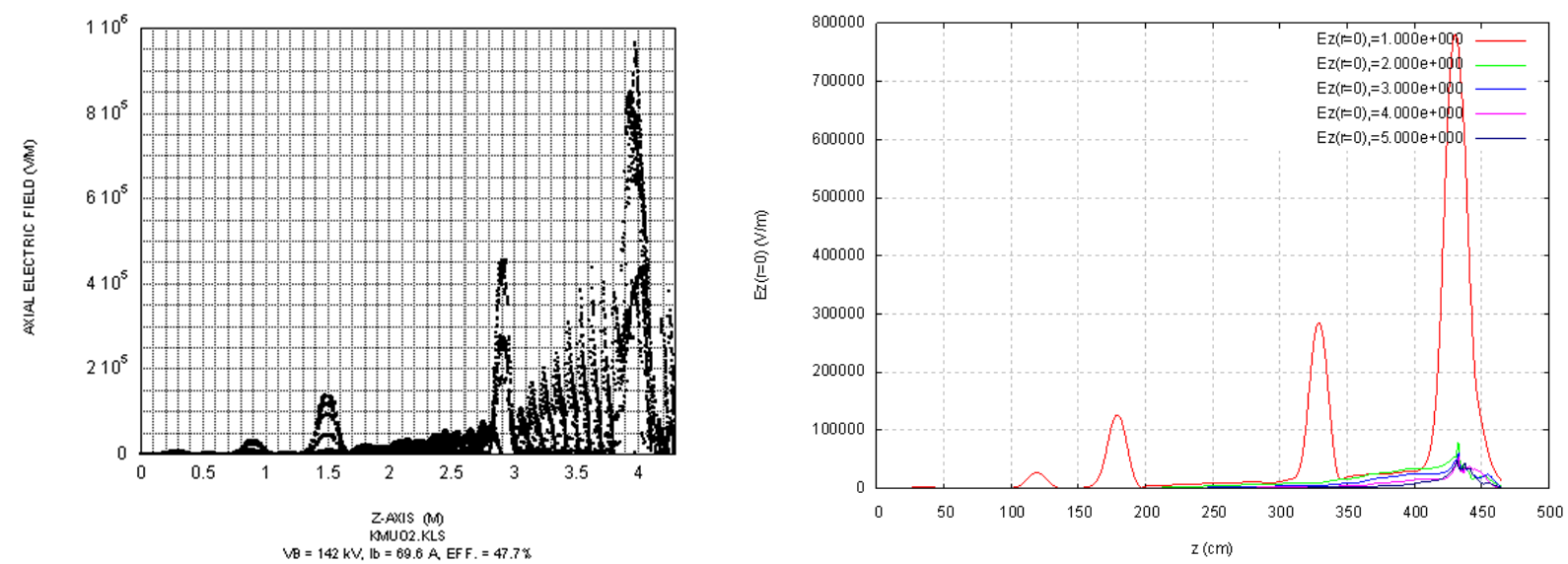

Figure 15. Gap electric fields as predicted by KLSC (left) and TESLA (right) 

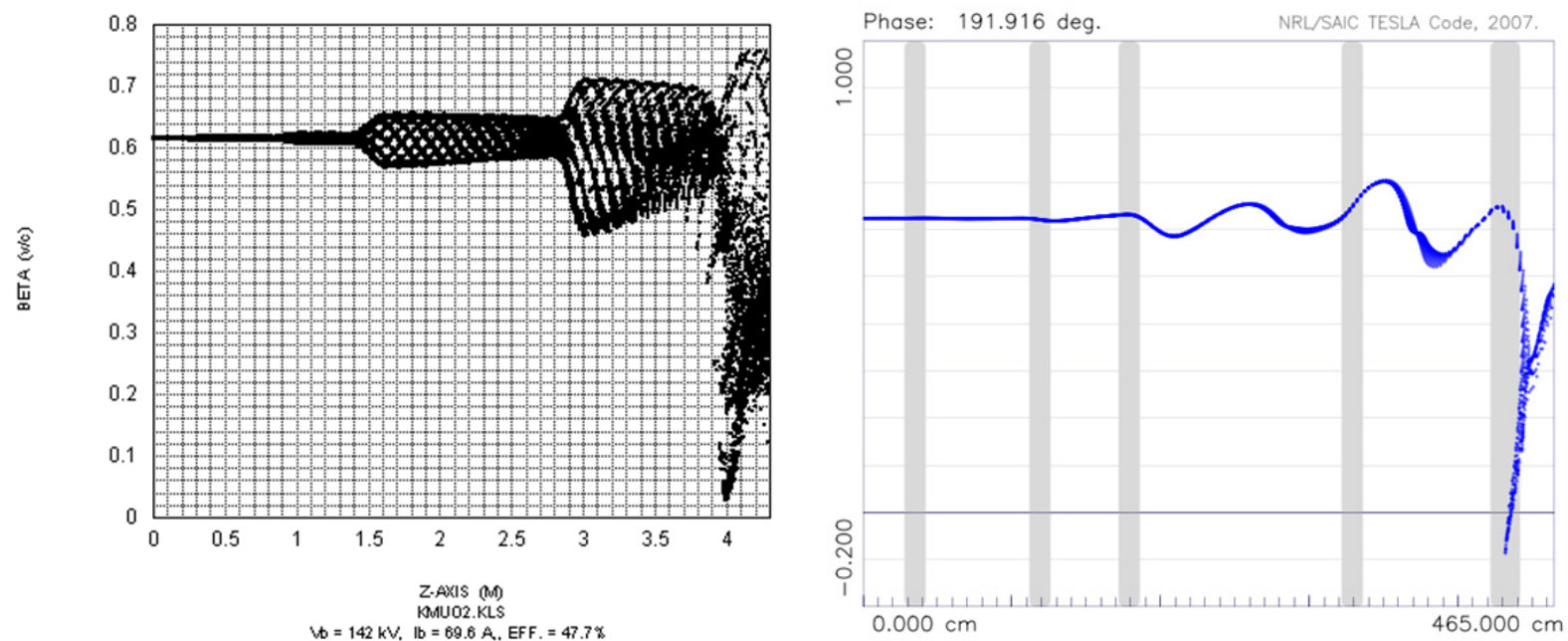

Figure 16. Electron velocities as predicted by KLSC (left) and TESLA (right)

TESLA is capable of modeling all beams in a multiple beam device. Figure 17 presents the circuit parameters for the eight beam simulation. The R/Q values were obtained from HFSS.The following results compare the single beam and multiple beam analyses.

$\begin{array}{ccccc}\text { Cav } & \text { Type } & \text { gaps } & \text { drift : Gap } \neq 1 \text { offset: Gap } \# 2 \\ 1 & \text { input } & 1 & 84 & 14.30 \\ 2 & \text { idler } & 1 & 60 & 14.30 \\ 3 & \text { idler } & 1 & 150 & 14.30 \\ 4 & \text { idler } & 1 & 100 & 14.30 \\ 5 & \text { output } & 1 & 0.0 & 20.00\end{array}$

\begin{tabular}{|c|c|c|c|c|c|c|c|c|c|c|}
\hline Cav $\#$ & Mode\# & $f[\mathrm{GHz}]$ & Q_ext & Q_ohm & PhaseM & Beam\# & shape & $R / Q$ & $I_{-} R / Q$ & Phase \\
\hline$-\infty$ & - & & & & 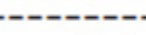 & & & & & \\
\hline 1 & 1 & 0.20125 & 300.0 & 10000.0 & 0.0 & 1 & flat & 30.4 & 0.0 & 0.0 \\
\hline 2 & 1 & 0.19950 & 0.0 & 10000.0 & 0.0 & 1 & flat & 30.4 & 0.0 & 0.0 \\
\hline 3 & 1 & 0.20370 & 0.0 & 10000.0 & 0.0 & 1 & flat & 30.4 & 0.0 & 0.0 \\
\hline 4 & 1 & 0.21700 & 0.0 & 10000.0 & 0.0 & 1 & flat & 30.4 & 0.0 & 0.0 \\
\hline 5 & 1 & 0.20125 & 10.47 & 10000.0 & 0.0 & 1 & flat & 37.0 & 0.0 & 0.0 \\
\hline
\end{tabular}

Figure 17. Cavity parameters for TESLA simulation of the eight beam klystron circuit 
Figure 18 shows the growth of the output power with time for the single and eight beam simulations. The output power for the eight beam circuit is approximately eight times the single beam output power.
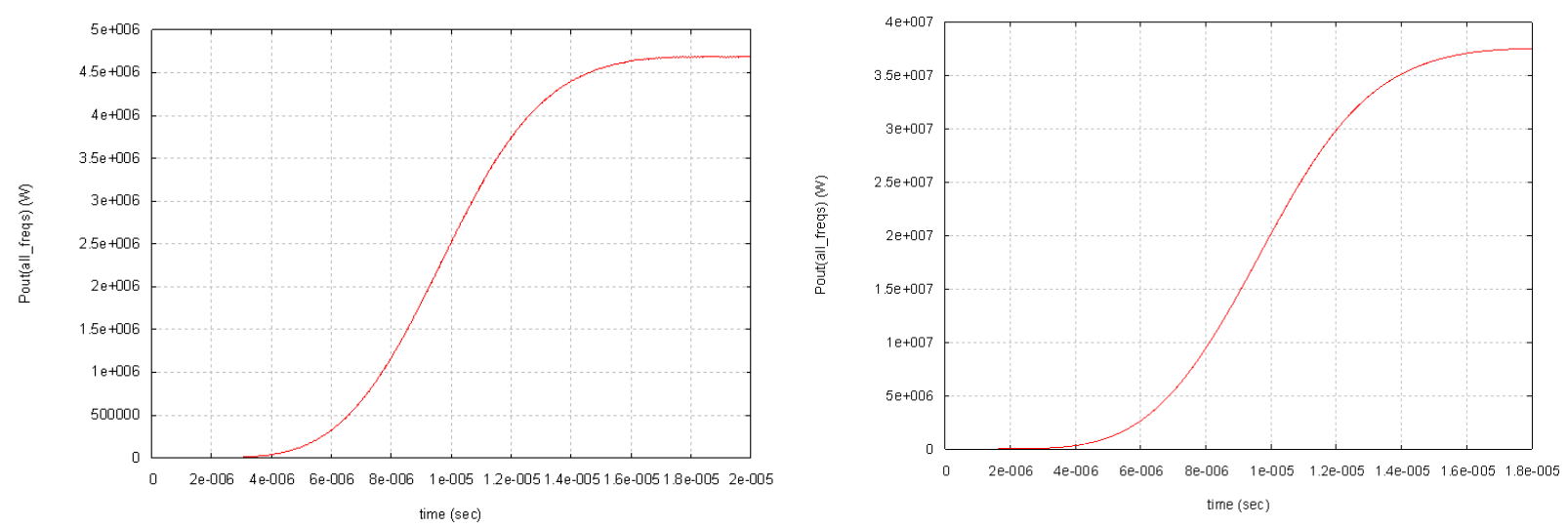

Figure 18. Predicted output power from single beam simulation (left) and eight beam simulation (right)

Figure 19 shows that the gap voltages for the two simulations are essentially identical.
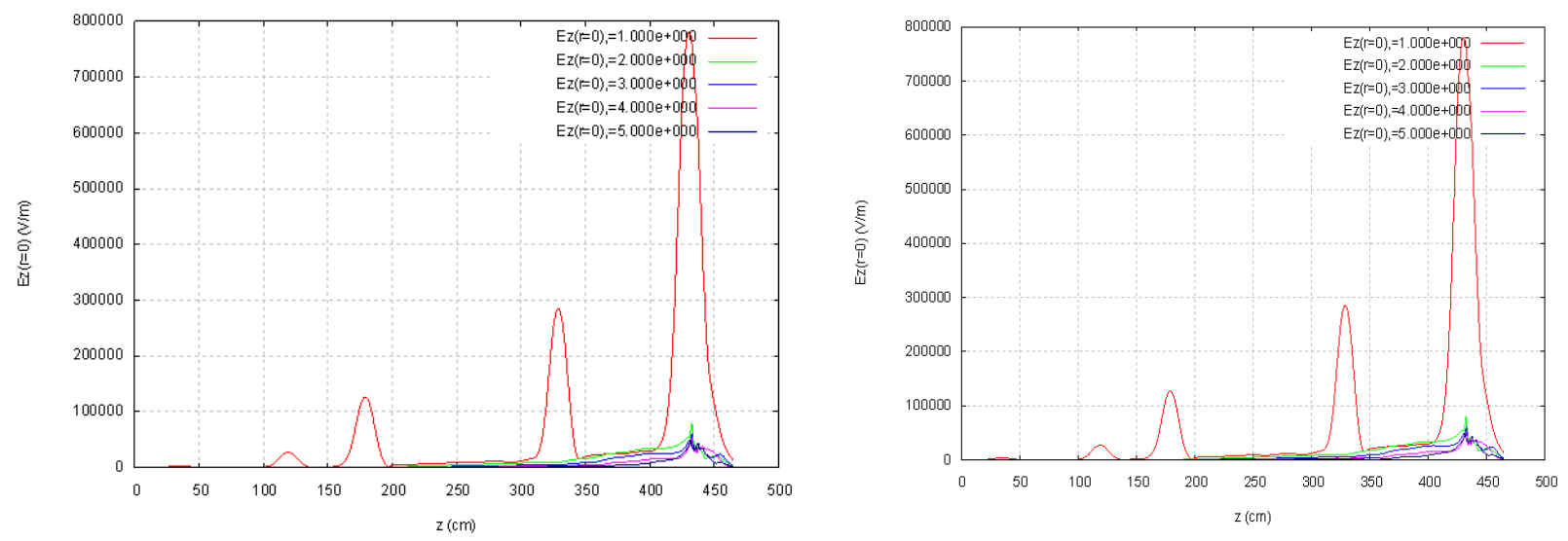

Figure 19. Gap voltages for single beam simulation (left) and eight beam simulation (right). Note that the plots also include contributions from harmonics.

This task developed a circuit that achieves the program goals as modeled by two, independent, large-signal analysis programs using different algorithms. The codes are in close agreement on all critical performance parameters. In addition, the multi-beam analysis of TESLA confirmed the validity of using a single beam model and scaling by the number of beams. The agreement between and within codes provides high confidence in the validity of the results. 
Task 5. Design additional components, including the magnet, input and output windows and couplers, and the spent beam collector

The components investigated in this task are very similar to those previously developed by CCR for a $5 \mathrm{MW} \mathrm{MBK}$ at this frequency. That magnet used a series of individual coils and iron plates to generate the flat field through the gun and through the output cavity. Figure 20 shows a model of the geometry. The only change from the previous design is a moderate increase in length and an increase in the field value from $200 \mathrm{G}$ to $278 \mathrm{G}$. The diameter of the coils and the location of iron structures are nearly identical.

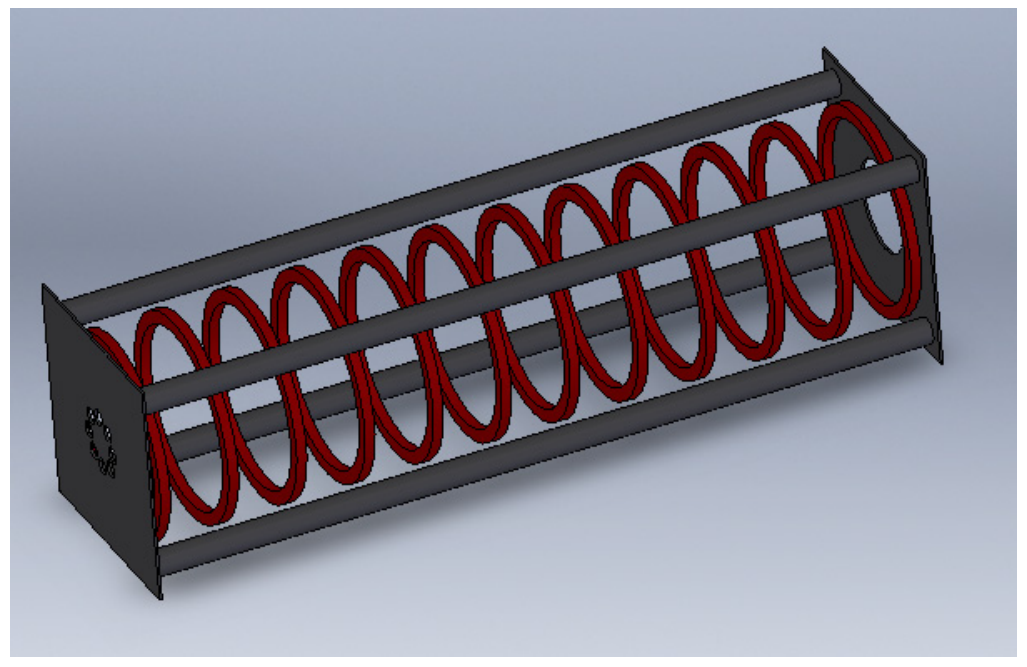

Figure 20. Magnetic circuit for a $200 \mathrm{MHz}$ multiple beam klystron

The klystron would use two coaxial windows located $180^{\circ}$ apart. The output window is also nearly identical to that in the previous design. The only modification is additional rounding of edges to reduce field gradients from the increased power level. Figure 21 shows a VSWR plot for the window.

The cooling requirement depends on the average power of the window. A detailed thermomechanical analysis was not performed during the Phase I program, since the window average power requirement is

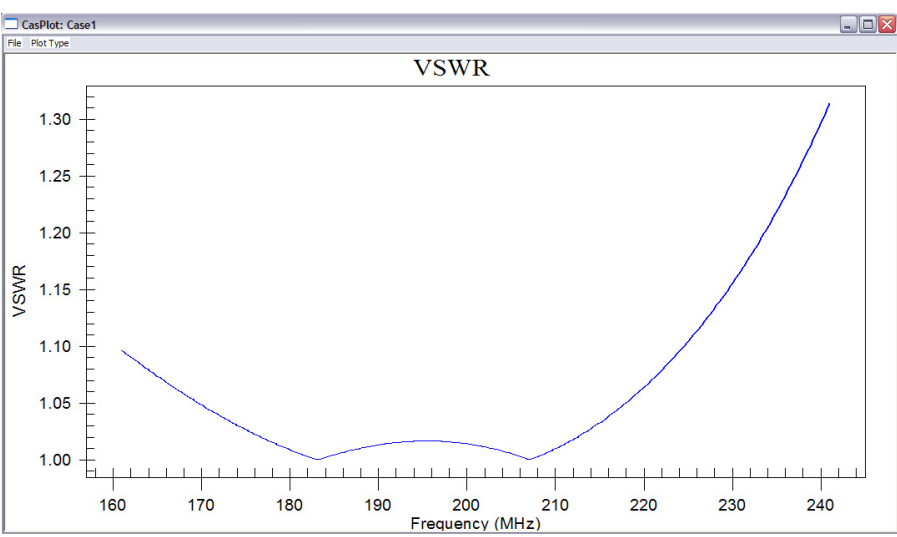

Figure 21. VSWR versus frequency for a 200 $\mathrm{MHz}$ coax window less than $50 \mathrm{~kW}$. The design uses AL995 ceramic, which has relatively low RF loss. CCR previously designed a similar window transmitting $200 \mathrm{~kW} \mathrm{CW}$ at $350 \mathrm{MHz}$. The design includes cooling on the outer diameter as well as the inner diameter. Once the average power requirement is more clearly defined, CCR is confident a robust window design can be achieved.

Mulitpactor will be a critical issue for the window because of the high peak power. CCR produces several high power RF windows with multipactor suppression coatings. CCR was selected for a DOE-funded 2010 Phase I STTR award to develop advanced multipactor coatings for RF windows.

The input signal will be coupled to the input cavity using a standard coaxial connector. It is assumed that the input signal will be transmitted through a coax cable; however, other configurations can easily be implemented. 
The MBK would use a common collector as shown in Figure 5. Results from beam simulations are shown in Figure 22. These simulations were for operation without generation of RF power. This represents the worst case for power deposition, since all the original beam power remains. The maximum pulse power density is $5.6 \mathrm{~kW} / \mathrm{cm}^{2}$. This would increase the temperature of the collector surface approximately $17^{\circ} \mathrm{C}$ during each pulse. This is well below damaging thresholds. With a duty cycle of $1 \%$ or less, the average power density is also very small and easily cooled.
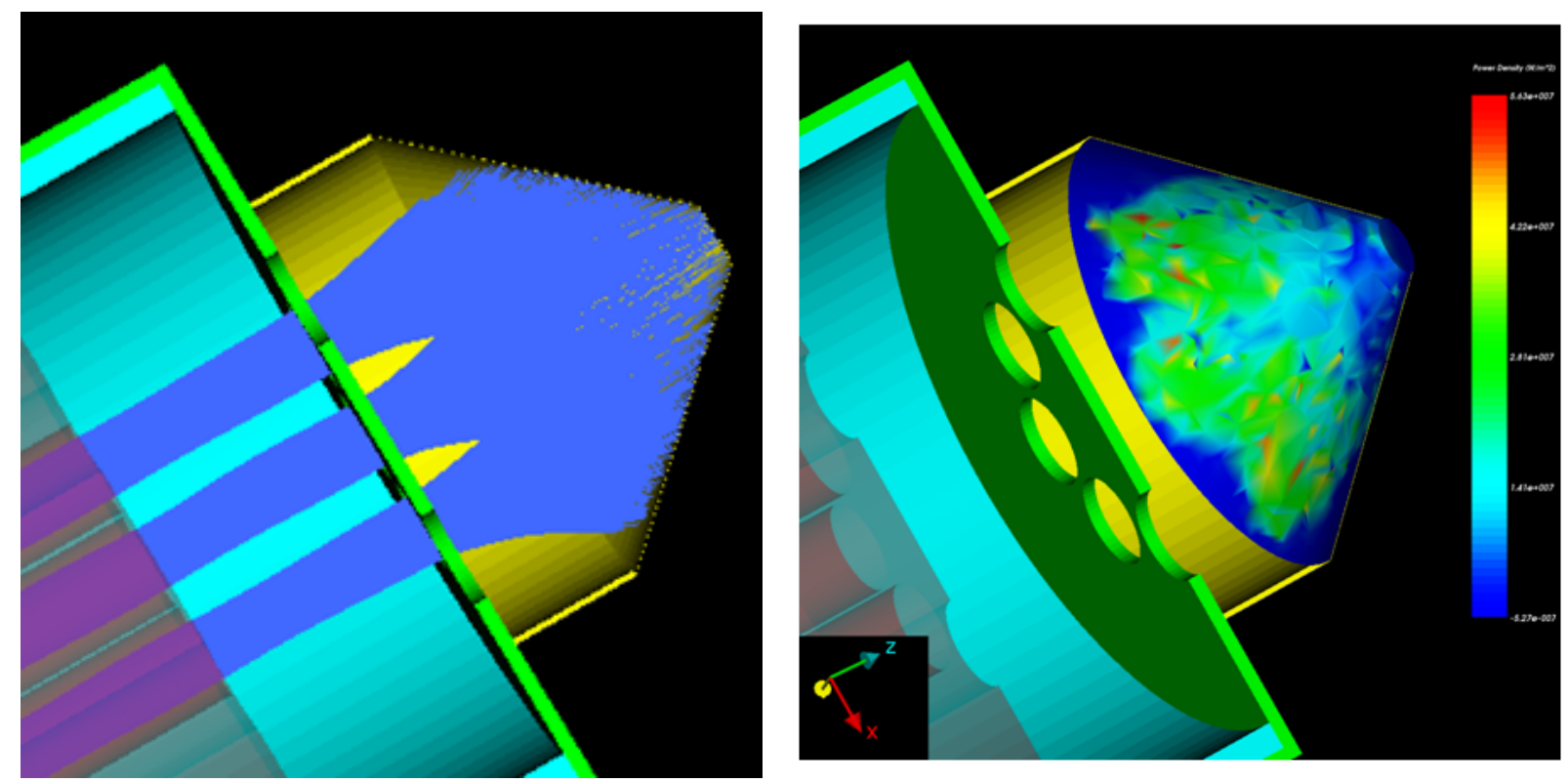

Figure 22. Collector simulation with three of the eight electron beams. The left image shows the electron trajectories, and the right image shows the power densities. The maximum value on the scale is $5,630 \mathrm{~W} / \mathrm{cm}^{2}$ and the lowest value is zero.

In some MBKs, potential depression of the beam in the relatively large collector chamber can reflect low energy electrons. For the $200 \mathrm{MHz}$ design, the potential depression is approximately $3000 \mathrm{~V}$. This is relatively insignificant compared to the beam voltage of $142 \mathrm{kV}$. Nevertheless, when energy is extracted from the beam by RF generation, the beam will propagate slower with increased depression; consequently, some reflection could occur. Fortunately, it is relatively simple to add a grounded conductor on the tube axis to reduce the depression. This is commonly used in multiple beam devices. This can be easily cooled because of the low beam power density. Figure 23

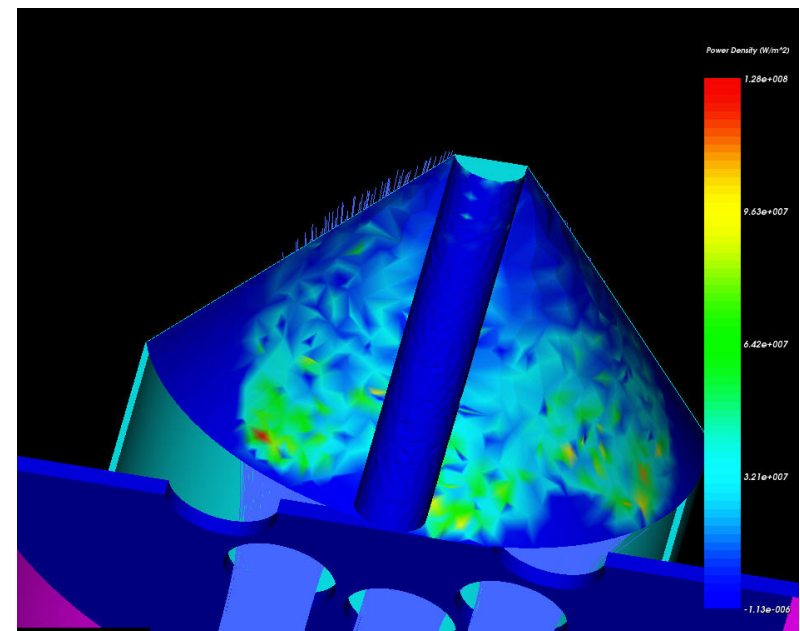

Figure 23. Preliminary collector design with central, grounded conductor shows a thermal simulation of a preliminary design. The power density on the center conductor is very low. 


\section{Task 6. Develop a preliminary mechanical design for construction of the klystron}

Figure 24 shows a solid model of the 35 MW MBK klystron, and Figure 25 shows the klystron in the magnet. The total length is approximately 16 feet with a maximum diameter of 38 inches. Estimated weight is approximately $12,000 \mathrm{lbs}$; however, no effort was devoted to weight reduction in the Phase I program. It is anticipated that the cavities will be fabricated primarily from stainless steel. Surfaces subjected to beam impact or high thermal loading will be made from copper or copper plated, whichever is most appropriate. The collector would be fabricated from copper. Tube weight could be minimized in a follow-on program.

The gun ceramic would be sized to allow air operation. Air operation would significantly ease the installation and reduce environmental problems. The high voltage surfaces would be inside the magnetic circuit, which would provide additional safety.

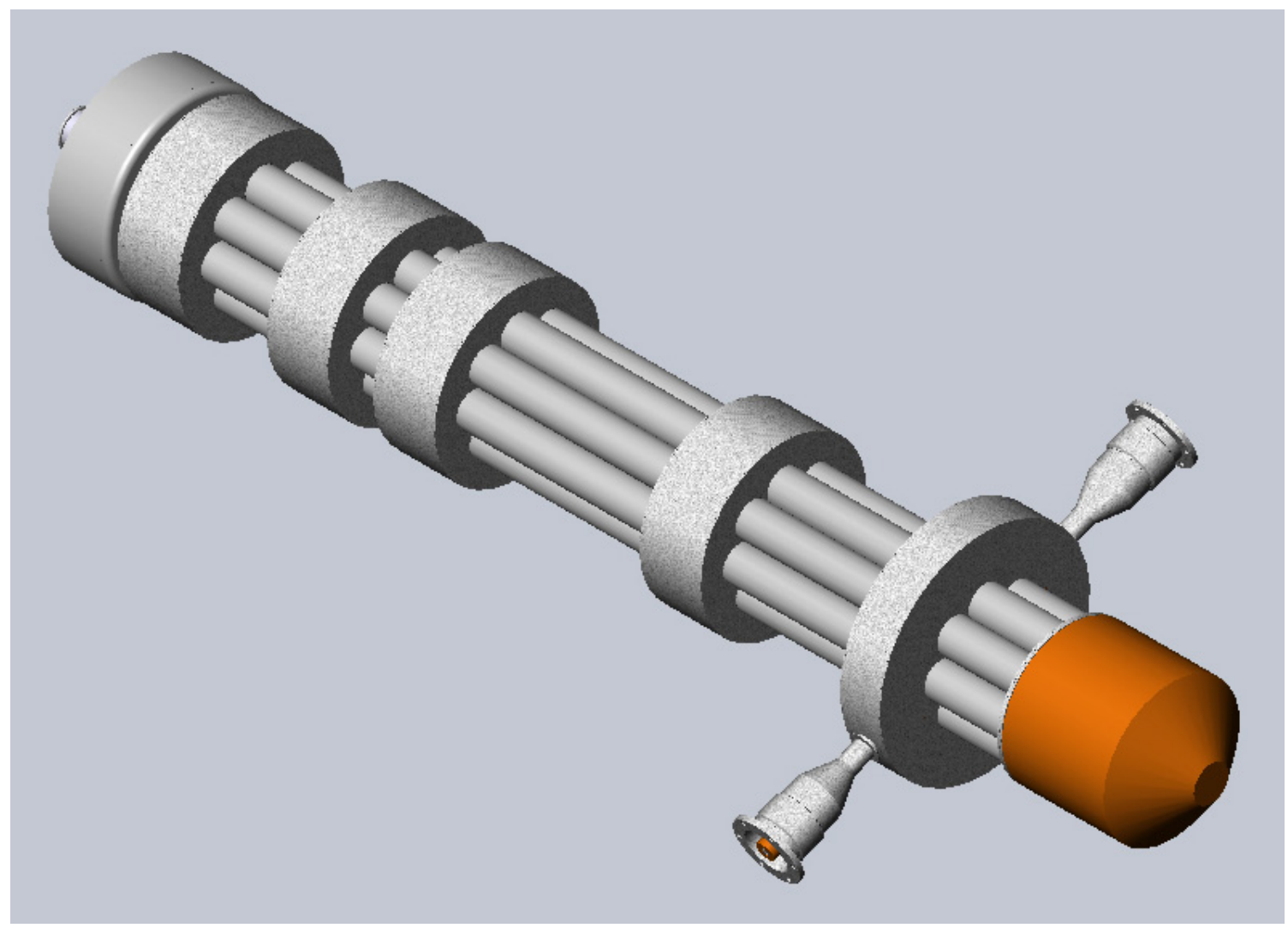

Figure 24. Solid model of $35 \mathrm{MW}, 201 \mathrm{MHz}$ multiple beam klystron preliminary design

The tube would require special handling for bakeout. It is not clear that an available bakeout station would be available to accommodate the entire tube. If not, each major subassembly would be baked in a vacuum oven, and the entire tube would be baked using heat tapes or some other mechanism. Since this is a short pulsed device, vacuum is not as critical as in a high duty device. Also recall that the focus electrode operates with extremely low electric fields. The primary vacuum consideration would be ensuring that the cathodes are not poisoned and that there would not be RF breakdown in the output cavity or the output windows. 


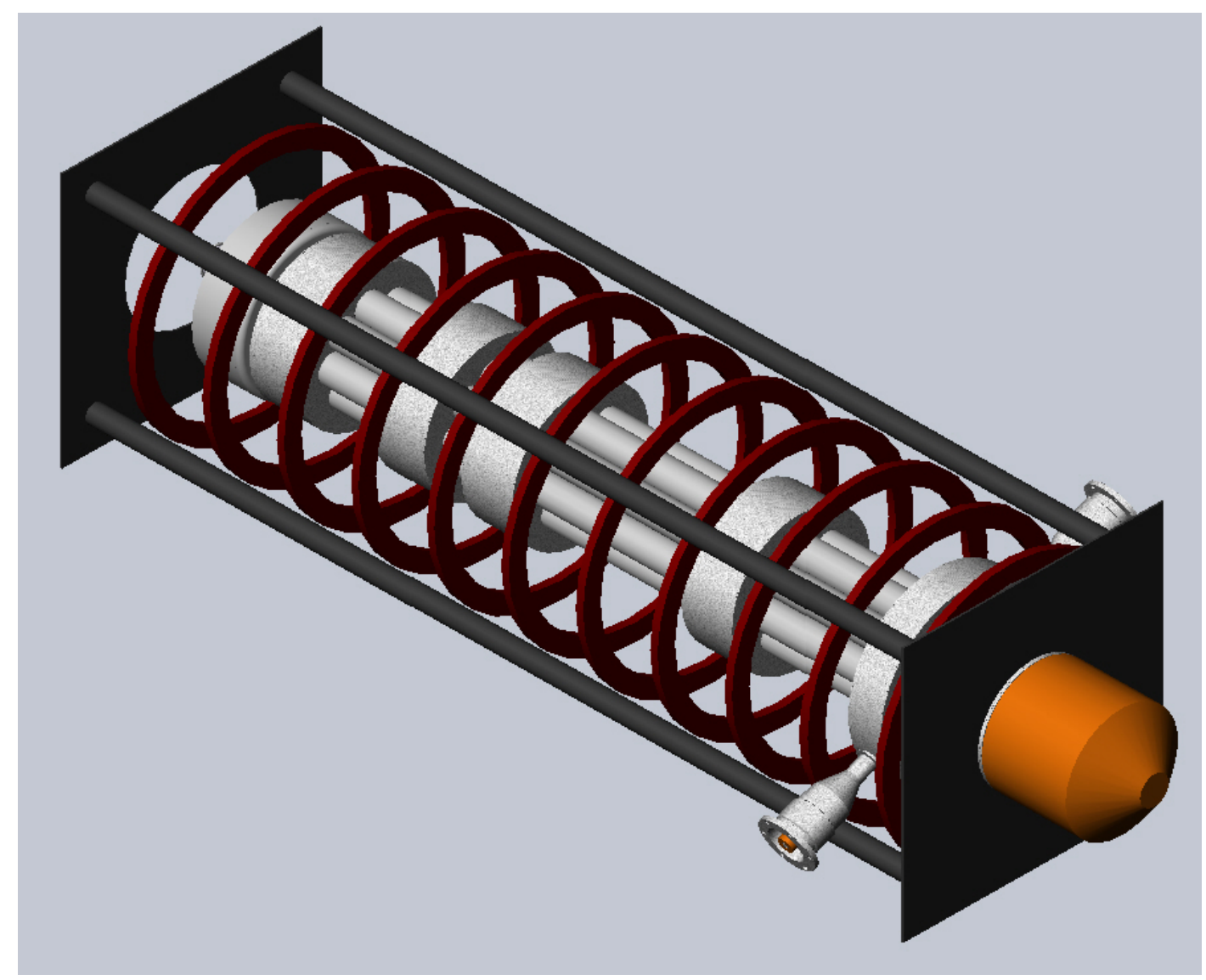

Figure 25. $35 \mathrm{MW}$ MBK in magnetic circuit

\section{Summary}

The Phase I program clearly demonstrated that a $35 \mathrm{MW}, 200 \mathrm{MHz}$ multiple beam klystron is feasible. The performance specifications required for the muon collider application were achieved.

\section{References}

1. Development of Multiple Beam Guns for High Power RF Sources for Accelerators and Colliders, U.S. Department of Energy Small Business Innovation Research Program, DEFG03-00ER82964, Sept. 2001-June 2004.

2. Flow Multiple Beam Guns for High Power RF Applications, R.L. Ives, M. Miram, A. Krasnykh, Valentin Ivanov, 13th IEEE Conf. Plasma Sci., Las Vegas, NM, June 2001.

3. "Development of Multiple Beam Guns for High Power RF Sources" Advanced Accelerator Concepts Ninth Workshop, AIP Conf. Proc. 569, Santa Fe, NM, October 2000.

4. Development of a 50 MW Multiple Beam Klystron, U.S. Department of Energy Small Business Innovation Research Program, DE-FG03-02ER83379, July 2002 -June 2005.

5. Development of a $200 \mathrm{MHz}$ Multiple Beam Klystron, U.S. Department of Energy Grant No. DE-FG02-04ER83916, July 2004 through March 2005. 
6. Dome Cathode, U.S. Patent Application Serial Number 11/173,107. Last office action April, 2008.

7. B.E. Carlsten, P. Ferguson, "Large-signal klystron simulations using KLSC" Proceed. 1997 Particle Accel. Conf., Volume 3, pp. 3129-3131, 1997.

8. I.A. Chernyavskiy et al, "Parallel Simulation of Independent Beam-Tunnels in Multiple Beam Klystrons Using TESLA,” IEEE Trans. Plasma Sci., Vol. 36, Issue 3 pp. 670-681, June 2008.

9. S.J. Cook, et al, "Validation of the large-signal klystron simulation code TESLA," IEEE Trans. Plasma Sci, Vol. 32, Issue 3, pp. 1136-1146, June 2004.

10. R.T. Longo, E.A. Adler, L.R. Falce, "Dispenser Cathode Life Prediction Model, IEDM 1984, pp. 318-321.

11. J. Neilson, R. Ives, and W. Vogler, "Cascade - An advanced computation tool for waveguide system and circuit design,” IEEE Intern. Conf. on Plasma Sci., 1998.

12. Development of a 200 kW CW, 350 MHz, Multiple Beam Inductive Output Tube, U.S. Department of Energy Small Business Innovation Research Grant No. DE-FG0207ER84876, June 2007 through August 2010.

13. $20 \mathrm{~kW}$ CW L-Band Klystron for Driving Superconductor Accelerator Cavities, U.S. Department of Energy Grant No. DE-FG02-03ER83833, June 2003 through December 2006. 